\title{
Maneiras de pensar e de agir de idosos frente às questões relativas à funcionalidade/incapacidade
}

\author{
Ways of thinking and acting of the elderly \\ when tackling functionality/disability issues
}

Josianne Katherine Pereira ${ }^{1}$

Josélia Oliveira Araújo Firmo ${ }^{1}$

Karla Cristina Giacomin ${ }^{2}$

${ }^{1}$ Centro de Pesquisas René Rachou, Fiocruz. Av. Augusto de Lima 1715, Barro Preto. 30.190-002 Belo Horizonte MG Brasil. josikatherine@yahoo.com.br ${ }^{2}$ Prefeitura Municipal de Belo Horizonte.

\begin{abstract}
Functionality is a crucial dimension of the health of the elderly. The aim of this work is to investigate the elements that comprise the significance of disability for the elderly residents of the city of Bambui in the state of Minas Gerais. A qualitative approach was adopted in which the model of signs, significance and actions was used in both data collection and analysis. Interviews were conducted with 57 elderly individuals (30 women; $27 \mathrm{men}$ ) ranging from 61 to 96 years of age registered in primary care units. The participants interpret functionality/disability (disease) as "being able to cope/not being able to cope" or "being a burden" (illness) to others. "Not being able to cope" refers to the inexorable functional loss inherent to the aging process, while "being a burden" relates to the permanent condition of generating pain and suffering to both patient and care giver. The way to deal with the "not being able to cope" condition is related to resignation. On the other hand, praying is the way to deal with "being a burden." Religion and resignation can help during critical moments, though they also reveal the lack of resources and alternatives for support and intervention in the most severe cases.
\end{abstract}

Key words Anthropology, Elderly individuals, Disability, Functionality
Resumo A funcionalidade é uma dimensão crucial da saúde da pessoa idosa. O objetivo desse trabalho é investigar os elementos que participam da construção dos significados da incapacidade para o idoso residente na cidade de Bambuí (MG). Trata-se de uma abordagem qualitativa na qual o modelo de signos, significados e ações foi utilizado na coleta e análise dos dados. Foram entrevistados 57 idosos (30 mulheres; 27 homens) com idades entre 61 e 96 anos, cadastrados nas Unidades Básicas de Saúde (SUS) da cidade. Os idosos compreendem a funcionalidade/incapacidade (disease), como o "dar conta/não dar conta" ou "dar trabalho" (illness). "Não dar conta" refere-se às perdas funcionais inexoráveis atribuídas à velhice, enquanto "Dar trabalho" a uma condição definitiva que gera dor e sofrimento à pessoa e a quem dela cuida. As maneiras de lidar com o "não dar conta" passam por se conformar, enquanto com o "dar trabalho", orar. A religiosidade e conformismo podem ajudar nos momentos de crise; mas, revelam a carência de recursos e de alternativas de apoio e de intervenção nos casos mais graves.

Palavras-chave Antropologia, Idoso, Incapacidade, Funcionalidade 


\section{Introdução}

No Brasil, o envelhecimento populacional é um fenômeno que se iniciou a partir da década de sessenta do século passado, quando começaram a diminuir as taxas de fecundidade e mortalidade infantil. Embora em nosso país esse processo seja marcado por grandes desigualdades e injustiças sociais ${ }^{1}$, é incontestável que o aumento da população idosa e da expectativa de vida represente um avanço para a sociedade ${ }^{2}$.

Nesse contexto, é fundamental compreender o envelhecimento populacional como um processo multifacetado e não generalizável ${ }^{3}$, no qual a funcionalidade se torna uma preocupação maior da saúde pública ${ }^{4}$. Com ele, entram em pauta, no cuidado à pessoa que envelhece ${ }^{5}$, a promoção do envelhecimento ativo e as questões relativas à capacidade funcional. Além disso, esta última constitui área chave de pesquisas e serve como balizadora de ações ${ }^{4}$, políticas e programas, aos quais serão ainda mais efetivas caso respondam às necessidades percebidas pelos indivíduos ${ }^{6}$.

Assim, a Antropologia se apresenta como o campo de conhecimento adequado para abordar a funcionalidade, dando voz aos interessados - as pessoas idosas - e possibilitando a construção conjunta dos projetos e ações necessárias. Contudo, desencontros entre os saberes biomédicos e os saberes populares sobre as questões relativas à saúde são frequentes, sendo, possivelmente, mais ricas as práticas que possibilitem o trânsito livre dos saberes além dos biomédicos ${ }^{7}$.

Para o profissional da saúde pode ser difícil compreender o corpo, a doença, a dor e o sofrimento como fenômenos culturais, pois ele aprendeu a reconhecer esses fenômenos segundo uma referência epistemológica totalmente diferente daquela do campo simbólico da antropologia ${ }^{8}$. Portanto, o estudo da funcionalidade/incapacidade como fenômeno sociocultural poderia minimizar as dificuldades na comunicação entre profissionais e idosos, além de atenuar a adversidade e auxiliar no manejo do ambiente social e físico, capacitando o idoso para melhorar seu senso de autoeficácia e de controle sobre a situação?.

Porém, nesse campo do conhecimento, persistem lacunas a serem exploradas no entendimento de como os idosos constroem o significado da incapacidade; lidam com ela e ou com sua perspectiva; e como as relações sociais e o contexto cultural modulam tal processo. Estudos antropológicos que descrevam a experiência subjetiva das pessoas idosas no seu cotidiano podem contribuir para a compreensão dos valores e normas culturais que participam das questões relativas à saúde ${ }^{10}$; dos sentidos e significados atribuídos à funcionalidade, à incapacidade e ao envelhecimento ${ }^{10}$; e das práticas e comportamentos assumidos diante desses processos ${ }^{10}$. Assim, o objetivo desse artigo é investigar os elementos que participam da construção dos significados da incapacidade para o idoso residente na cidade de Bambuí (MG).

\section{Metodologia}

\section{Quadro Teórico}

Sob o ponto de vista da Antropologia da saúde, a doença não pode ser definida apenas como um processo patológico, no sentido biomédico do termo, o processo saúde/doença é uma construção sociocultural. Nessa perspectiva, vários estudiosos, entre eles Eisenberg ${ }^{11}$ e Kleinman ${ }^{12}$, elaboraram conceitos e formas de compreender a doença que ainda são usadas até hoje ${ }^{13}$. A teoria proposta por Eisenberg ${ }^{11}$ diferencia a "doença processo" e "doença experiência". Segundo ele, a "doença processo" (disease) se refere às anormalidades dos processos biológicos e psicológicos, na função e/ ou estrutura dos órgãos e sistemas do corpo, e a "doença experiência" (illness) à experiência subjetiva de mal-estar. Kleinman ${ }^{12}$ desenvolveu o conceito de "modelos explicativos" (explanatory models) para descrever o conjunto de crenças e expectativas sobre uma doença, formuladas por indivíduos em uma determinada cultura. De acordo com essa perspectiva, o modelo biomédico de compreensão do processo saúde/doença é apenas uma das maneiras de interpretar esse fenômeno e é também social e culturalmente construído ${ }^{14}$.

\section{Percurso metodológico}

A presente pesquisa antropológica utiliza a abordagem qualitativa, visando a valorização das interpretações dos idosos. Foi realizada na cidade de Bambuí, um município que possui atualmente uma população de aproximadamente 23.000 habitantes, incluindo zona rural e urbana. O município passa por progressivo fenômeno de urbanização, semelhante ao Brasil após 1950, podendo-se verificar uma redução da população rural que representava $84 \%$ em 1950 , e passou para $27 \%$ em 1991, chegando a apenas $15 \%$ da população total do município em 2010. Quanto à composição etária, observa-se o envelhecimento progressivo e acelerado da sua população: em 1960, 3,8\% dos habitantes apresentavam 60 ou mais anos de idade; 
em 1970 esta proporção era de 5,1\%, em 1980, de $7,3 \%$, chegando a $15,9 \%$ de idosos, em 2010 , segundo o último censo do IBGE ${ }^{15}$.

Quanto às questões relativas à saúde, Bambuí se destacou como centro de profilaxia contra a doença de Chagas. O posto Avançado de Estudos Emanuel Dias, criado para controle desta doença presta até hoje assistência médica à população, integrando o Sistema Único de Saúde. Além dele, a rede pública de assistência à saúde do município conta com seis Unidades Básicas de Saúde que integram a Estratégia Saúde da Família, um Centro de Saúde, uma unidade do Núcleo de Apoio à Saúde da Família (NASF), um hospital da Fundação Hospitalar do Estado de Minas Gerais (FHEMIG) e um hospital municipal, o Hospital Nossa Senhora do Brasil. Inexistem instituições de longa permanência para idosos ${ }^{16}$.

\section{População de estudo}

Os idosos (idade mínima de 60 anos) que participaram desse estudo foram selecionados entre aqueles cadastrados em Unidades Básicas de Saúde da cidade.

A escolha dos entrevistados baseou-se em critérios que visaram garantir a heterogeneidade dos participantes. Dessa forma, foram selecionados idosos, de ambos os sexos, que conseguiam responder às perguntas sem precisar de nenhuma ajuda ou apoio de terceiros. Quanto às condições de saúde, de acordo com os relatórios de profissionais que os atendiam em uma das seis UBS da cidade, os entrevistados apresentavam alguma(s), muita(s) ou nenhuma doença incapacitante.

O critério de saturação foi utilizado para regular o número de entrevistas ${ }^{17}$.

\section{Coleta dos dados}

No presente trabalho, o modelo de Corin et al. ${ }^{18}$ foi utilizado na coleta e análise dos dados, para permitir a sistematização dos elementos do contexto que participam da construção de maneiras típicas de pensar e agir diante da incapacidade ${ }^{10}$.

Para reconstruir o universo de representações (maneiras de pensar) e comportamentos (maneiras de agir) associados à incapacidade pelos idosos residentes em Bambuí, foram realizadas entrevistas semiestruturadas no domicílio do entrevistado, após apresentação e assinatura do termo de consentimento livre e esclarecido. Inicialmente, as entrevistas tiveram como perguntas geradoras: a) Como você acha que está sua saúde? b) Para você, o que é uma saúde boa? E saúde ruim? c)
Como é o seu dia-a-dia, sua rotina? Como é um dia em sua vida?

A partir das respostas obtidas, outras perguntas foram feitas abordando o contexto biopsicossocial, os recursos, o impacto e o significado da incapacidade. As entrevistas foram gravadas para possibilitar a análise mais cuidadosa e detalhada dos dados.

\section{Análise dos dados}

Primeiramente, as entrevistas foram transcritas e lidas várias vezes. Após essa primeira fase da análise, algumas frases, palavras, adjetivos, concatenação de idéias, sentido geral do texto, foram destacados. Para a elaboração das categorias centrais, os seguintes passos foram seguidos:

A análise visou identificar "os sistemas de signos, significados e ações”, ou seja: a) os diferentes tipos de signos associados à identificação de um determinado problema, à gravidade desse problema ou à necessidade de tratamento; b) as explicações privilegiadas frente a esses signos e c) as reações e ações que são desencadeadas por esses $\operatorname{signos}^{10}$. Foram examinadas as articulações entre "os sistemas de signos, significados e ações" em relação a diferentes elementos do contexto pessoal, social e cultural sobre a construção e a evolução das reações e dos comportamentos ${ }^{10}$.

Emergiu da análise a relevância das questões da funcionalidade/incapacidade para explicar o processo do adoecimento dos idosos entrevistados, o que permitiu elaborar as categorias centrais que representam os significados de funcionalidade/ incapacidade atribuídos pelos idosos.

Para assegurar o anonimato, os entrevistados foram identificados pelo sexo, pelo número da entrevista e pela idade. Para exemplificar: a primeira mulher entrevistada foi identificada como Mulher 1 (M 1, 70 anos), a segunda, Mulher 2 (M 2, 87 anos) e assim sucessivamente.

\section{Aspectos éticos}

Essa pesquisa é parte de um projeto maior intitulado "Abordagem antropológica da dinâmica da funcionalidade em idosos", aprovado pelo Comitê de Ética do Centro de Pesquisa René Rachou (Fiocruz).

\section{Resultados e discussão}

Foram entrevistados 57 idosos, 27 homens e 30 mulheres, com idades entre 60 e 96 anos, cadas- 
trados nas seis UBS da cidade de Bambuí, MG. Os entrevistados eram oriundos da zona rural, sendo o maior acesso a educação e trabalho para os filhos e a proximidade do serviço de saúde os principais motivos para a mudança para a cidade. Observou-se, nesta população, baixa escolaridade e forte influência da religião católica. A maior parte dos idosos referiu sua saúde como boa e esse construto se relacionava à capacidade funcional è̀ autonomia. Um idoso viúvo que morava sozinho e recebia apoio de uma filha para as atividades domésticas, analisou:

Tá boa [a saúde], porque eu tô sadio..., almoço e janto bem, durmo, tô feliz. (H 26, 85 anos).

Em outra pesquisa realizada com idosos residentes em Bambuí, a saúde era compreendida como a capacidade de permanecer ativo em termos de capacidades físicas e de mobilidade e de executar as próprias escolhas ${ }^{19}$. No entanto, embora a capacidade física seja considerada um balizador das concepções de saúde, ela sozinha não consegue elucidar toda a experiência dos entrevistados, pois as dimensões biológicas, sociais, culturais, econômicas também fazem parte desse processo ${ }^{20}$.

\section{A funcionalidade/incapacidade}

Compreender o sentido e o significado de uma condição de saúde é uma das tarefas do pesquisador que estuda a área sob o ponto de vista sócio antropológico. Embora se saiba que quaisquer modelos explicativos formulados pelo pesquisador jamais esclarecerão completamente o processo saúde/doença, demonstraremos nesse artigo as maneiras de pensar e de agir dos idosos entrevistados sobre a questão da funcionalidade/ incapacidade (disease). No grupo estudado, os idosos falaram de suas experiências (illness) a partir de dois principais signos referenciados: "Dou conta/ Não dou conta" e "Dar trabalho".

\section{Dou conta/Não dou conta}

Para os entrevistados, as noções de funcionalidade e incapacidade foram entendidas, respectivamente, como o que dou conta e o que não dou conta de fazer. Como esperado para esta geração, as atividades domésticas foram mais citadas pelas mulheres, como afirmou uma senhora:

Eu faço a comida, lavo a minha roupinha, mas ela [a filha] que faz a limpeza da casa, eu não dou conta... (M 51, 70 anos).

Enquanto não dar conta de trabalhar foi um signo recorrente, mais valorizado pelos homens. Os trechos a seguir exemplificam essa situação:
Porque eu não ando, não dou conta de trabalhar. Eu trabalhei 22 anos e agora tô aí parado. (H 6, 62 anos).

Sabe-se que na vida moderna e no mundo capitalista o trabalho produtivo é valorizado e a identidade do indivíduo é construída a partir dessas atividades remuneradas. Portanto, quando acontece $\mathrm{o}$ afastamento das funções profissionais, a pessoa deve reorganizar sua identidade, o que pode representar um período de estresse na vida desse indivíduo ${ }^{21}$.

Homens e mulheres que reportavam mais doenças apontavam dificuldades no auto-cuidado. Uma idosa que reclamava de dores no corpo, possivelmente decorrentes de uma doença reumatológica grave, lamentava sua limitação:

Ah... eu não consigo fazer nada! Eu também não alimento, comida, eu não como mais. Bebo assim um leite, um mingau, só... Não dou conta de fazer nada não. Nem assim de noite... não dou conta de puxar um lençol pra me cobrir com a mão... (M8, 83 anos).

Para os entrevistados não dar conta se referia a perdas que representavam uma condição inexorável da velhice. A velhice é utilizada como resposta para explicar as perdas progressivas na execução de tarefas cotidianas, além de justificar a perda da capacidade para trabalhar, quer seja na roça, nas tarefas domésticas ou na vida da cidade; como demonstram as falas a seguir a seguir:

E, trabalhar do jeito que era. Trabalhar em casa ou trabalhar na roça... eu fazia biscoito, eu tinha horta muito boa de verdura, eu gostava de plantar uns trem, agora não posso mais. (M 42, 82 anos).

Ah, quem tem 89 anos é diferente, já está mais fraca, sem disposição... (M 1, 89 anos).

Ah, eu não faço muito, não faço nada sozinho. Eu na idade que eu estou, não aguento fazer muita coisa. Mais é quieto. (H 45, 92 anos).

Falta de destreza, desânimo, cansaço, sem disposição foram outros signos associados às perdas funcionais relativas à velhice. Essa relação entre a velhice e as perdas funcionais e de energia foi discutida por Carade $\mathrm{c}^{22} \mathrm{em}$ um artigo baseado em uma série de entrevistas realizadas com sexagenários aposentados recentemente, octogenários e nonagenários. Nele, esse autor investigou a questão da sensação de envelhecer e da corporeidade e concluiu que o idoso vivencia o envelhecimento corporal por meio de três registros: o do corpo orgânico, o da aparência e o da energia. O registro do corpo orgânico relaciona-se às limitações funcionais e a doenças consideradas como sinais do envelhecimento. $\mathrm{O}$ registro da aparência se refere às dimensões plásticas do corpo que envelhece, como as rugas e os cabelos brancos. Por fim, o 
registro da energia, muito mais frequente entre os octogenários e nonagenários, faz referência à vitalidade do corpo e queixas como cansaço, fraqueza, falta de vontade, desânimo são expressões comuns que exemplificam esse registro de debilidade energética.

Em Bambuí, no campo de fala dos idosos, a primeira razão para explicar as dificuldades progressivas é a própria velhice, mas também foram citados: os comportamentos da juventude e as condições de trabalho que os teriam prejudicado. Para alguns entrevistados, ter alguma dificuldade ou estar doente era o fruto que estariam colhendo de uma vida difícil, da falta de cuidado que tiveram consigo mesmos ao longo da vida. O relato de uma idosa com dependência completa para o autocuidado exemplifica essa questão:

Ah, eu acho que eu mesma sou culpada. Ah porque eu trabalhava direto... Lavava roupa até... Enfiava a mão na água, tirava aquilo quente e tocava na água. Não havia máquina nem tanque tinha. Tudo na mão e era fervido... Na roça a gente molhava demais, esfriava muito... (M 8, 83 anos).

Nessa direção, Debert ${ }^{23}$ teoriza sobre o que chamou de "reprivatização da velhice", em que tanto os idosos, como toda a sociedade e até gerontólogos, reproduzem a ideia de que a velhice é um problema do próprio velho que não conseguiu cuidar de sua saúde quando era jovem e que, como sua condição está sob seu desejo e seu controle, quem quiser deixar de ser velho, deve seguir as orientações médicas cientificamente comprovadas. Nos registros dos idosos bambuienses, os profissionais da saúde também corroboram e reforçam essa ideia, como afirmou um senhor:

... [o médico] só falou comigo assim: 'o senhor não preocupa muito não, caça um jeito de ficar mais despreocupado, repouso, isso maior que você sente agora é idade. Essa idade da gente aparece uma coisinha aqui, aparece outra por lá, o senhor não tem que preocupar, não' (H7, 84 anos, casado).

Outra questão abordada na análise das entrevistas foi a maneira de agir diante das situações em que não davam conta. Nas narrativas dos idosos, diante da experiência ou do temor da incapacidade ou de algum problema de saúde, foram ações relatadas: adaptações na vida diária e ou o abandono de alguma(s) atividade(s); podendo a pessoa idosa agir de diferentes maneiras diante das dificuldades. Assim, mudar a forma de executar uma função, ou providenciar o uso de um dispositivo auxiliar para conseguir fazê-la, são exemplos das estratégias de adaptação utilizadas, como aparece no trecho selecionado a seguir:

A velhice... muda a vida da gente. Essa questão da força, de habilidade que podia ter e não tem. Não consegue mais fazer o trabalho. A oficina [de artesanato] ali é uma bagunça, porque pra pegar um objeto eu não posso agachar... Agora eu arranjei uma ferramenta... fiz uma ponta com imã na bengala, para pegar... (H 15, 75 anos).

Outra maneira era abandonar atividades, independentemente se realizadas nos ambientes doméstico, como "cozinhar", "lavar roupa para fora”, ou externo, como "ir à rua fazer compra”, "passear", "visitar amigos". Porém, a compreensão desse processo diferia conforme a pessoa idosa se sentisse ou estivesse no controle da situação. $\mathrm{Na}$ fala dos idosos, eles não se tornavam incapazes de fazer algo, eles deixavam de fazê-lo por livre escolha e/ou por saber que alguém se encarregaria da atividade. A fala de uma idosa viúva que recebe apoio de seus filhos reflete a relação entre o apoio familiar e o ato de deixar de fazer algo:

Tem quem faz e tem quem fica quieto. Se eu tenho quem faz... (M 5, 77 anos).

Ficar mais quieto era outra maneira de os entrevistados lidarem com as dificuldades, conforme ilustram os relatos abaixo:

Não faço mais nada... Quietei, mas quietei mesmo. Sempre eu vou lá na roça e só dou uma voltinha. (H 23, 82 anos).

As coisas, à medida que eu fui deixando de fazer certas coisas, ou modificando o jeito de fazer, é que melhorou um pouco... (M 10, 72 anos).

Maneiras semelhantes - adaptar-se e abandonar atividades - também foram vistas na população idosa estudada por Caradec ${ }^{22}$, nos grupos de sexagenários e octogenários. Segundo esse autor, diante das dificuldades diárias, os idosos criam estratégias de reconversão, como a adaptação, o abandono de atividades e a volta por cima. Ele cita como adaptação o uso de uma prótese auditiva, por exemplo; enquanto o abandono de atividades pode assumir a forma de:

- abandono-substituição: por exemplo, assistir missa pela televisão;

- abandono-seleção: por exemplo, dirigir por distâncias mais curtas; e

- abandono-renúncia: por exemplo, desistir de dirigir.

A volta por cima refere-se à retomada de uma atividade abandonada ou ao maior envolvimento em uma atividade já praticada, como é o caso de uma viúva que após a morte do cônjuge estabelece outras relações, participa de excursões. Caradec ${ }^{22}$ demonstra que os entornos sociais, como a ambiência adaptada para pessoas com dificuldades e a oferta de oportunidades de engajamento, favorecem a manutenção dos apegos à vida na 
pessoa idosa. Além disso, quanto ao abandono das atividades, é necessário esclarecer que, mediante a sensação de perda de força e vitalidade, se por um lado isso pode ser uma medida protetora, por outro pode levar a maiores dificuldades no futuro, pois parar de fazer as atividades piora a fraqueza muscular e o déficit de equilíbrio, por exemplo ${ }^{22}$.

No momento em que os idosos entrevistados relatam não dar conta de realizar algumas atividades, surge a indagação: quem faz o que precisa ser feito? Quem ou qual instituição representa esse apoio? De acordo com os entrevistados, compreende-se que basicamente assumem esse apoio: a família, os amigos e os vizinhos. A importância desse apoio social está registrada nos relatos a seguir, em que vários familiares são citados:

Tenho um neto aí que me ajuda... é ele que me dá banho, ... me ajuda a sentar para eu comer. Ele é tudo para mim. (H 36, 61 anos).

$E$, eu tenho um filho que às vezes vai para mim... O dia que eu não aguento mesmo, ele vai na farmácia para mim, vai no postinho marcar as consultas... Busca as coisas para mim quando eu preciso. (M 19, 83 anos).

Outra fonte de apoio social reconhecida pelos idosos foram os amigos e vizinhos, primordiais para aqueles que moravam sozinhos, principalmente nas questões relativas às doenças. Os vizinhos os levavam ao médico, realizavam o cuidado com a casa, ajudavam-nos a transitar pelo bairro e até ajudavam até financeiramente, além de tornar o abandono de algumas atividades menos difícil. $\mathrm{O}$ relato abaixo demonstra a importância desse tipo de apoio:

... estes vizinhos é uma família... quando eu adoeço, não falta gente, écarro para me levar, épara ficar comigo no Hospital... Assim, não é de dizer que precisar de alguma pessoa para me dar banho, coisa assim, não, mas assim, para ficar comigo no hospital... são gente muito boa. (M 24, 86 anos).

Em um artigo de revisão, Rosa e Benício ${ }^{24}$ relatam que $\mathrm{o}$ apoio social, no âmbito das redes sociais, pode ser compreendido como: a) apoio emocional, como demonstração de amor e afeto; b) apoio instrumental ou material presente na ajuda para trabalhos práticos (limpeza de casa, preparação de refeição, provimento de transporte) e na ajuda financeira; c) apoio de informação como aconselhamentos, sugestões, orientações; e d) interação social positiva que diz respeito à disponibilidade de pessoas com quem obter alguma forma de lazer e prazer. Ainda segundo essas autoras, a presença do apoio social tem impacto positivo sobre as condições de saúde, podendo inclusive reduzir o risco de mortalidade. Também no presente estudo, o apoio social pareceu ser decisivo para a vida daqueles entrevistados que envelheceram com alguma dificuldade na execução de tarefas. No entanto, vale ressaltar que, para os idosos participantes desse estudo, os serviços públicos de saúde foram fontes de medicamentos, consultas e realização de exames, mas não foram compreendidos como apoio social nem como forma de cuidado.

\section{Dar trabalho}

O outro signo associado ao termo biomédico "incapacidade" foi Dar trabalho. Ele era utilizado tanto por idosos que se diziam em boa saúde quanto pelos que se relatavam doentes. Uma idosa, viúva, que vivia restrita a seu domicílio por limitações decorrentes de doença reumatológica, justificou:

Eles [os filhos] peleja para eu sair, mas eu acho difícil demais, porque a gente dá trabalho, né? (M 8,83 anos).

No grupo entrevistado, grande parte dos idosos se considerava saudável, poucos se percebiam como dando trabalho e, aqueles que se queixavam de estar nessa condição, eram os mais doentes, com menos recursos financeiros e pouco suporte da família. Uma idosa que morava sozinha reclamava de dores na perna e de seu passado difícil, pois fora cuidadora da mãe, dos irmãos e precisou trabalhar, razão pela qual não se casou. Atualmente, vê-se sozinha ao enfrentar a doença e vivenciar as perdas funcionais:

Eu perdi o meu pai, eu tava com nove [anos]. Fiquei por conta dos irmãos e da minha mãe. Depois a mãe faltou e eu fiquei por conta dos irmãos, trabalhando. Parece que eu perdi a coragem... E a gente fica doente, a gente dá trabalho demais! (M 27, 80 anos).

Note-se que a expressão dar trabalho é usada para compreender diversas situações. Por exemplo, uma mãe costuma dizer que o bebê deu trabalho, o filho adolescente está dando muito trabalho ou ainda um estudante admitir que uma tarefa deu trabalho para ser concluída. Ainda que em situações diversas e com significados diferentes, em todos, a expressão dar trabalho reflete uma conotação negativa. Da mesma forma, no presente estudo: dar trabalho representa uma situação ruim, significando a dependência de outras pessoas. O relato abaixo exemplifica tal experiência de sofrimento:

Ah, eu penso que é ruim, fica dependendo, depende dos outros demais, né? Não pode fazer nada. Não é fácil não! (M 14, 88 anos).

No presente estudo, o signo dar trabalho se refere aos estágios mais avançados e mais graves 
de perdas funcionais e remete à necessidade de cuidado. Porém, no grupo pesquisado, as dificuldades no dia-a-dia somente são percebidas pela pessoa idosa quando sua condição de saúde fica mais grave, com maior sofrimento tanto para o próprio idoso quanto para quem dele cuida. Isso sugere que, na velhice, a incapacidade permanece invisível para o sujeito até o momento em que a necessidade de um terceiro não the permite mais escondê-la. Além disso, mesmo entre aqueles que não haviam vivenciado a experiência de dar trabalho, a expectativa de vir a fazê-lo representava sofrimento, pois:

- teriam de lidar com o fato de não conseguirem mais, respectivamente, realizar atividades e ou exercer papéis sociais que um dia haviam sido capazes de fazer; e ou

- temiam não serem bem cuidados pelos familiares ou ainda não ter alguém para realizar esse cuidado.

Essas situações estão claramente expressas nos relatos de mulheres e homens idosos, como se pode perceber na fala a seguir:

... medo de dar trabalho aos outros eu tenho por que... uma comparação: numa família tem gente de muito tipo. Um faz aquilo com carinho, com amor, outro já faz aquilo contrariado e às vezes fica com vergonha de ver os outros fazer e ele não fazer nada... (H 7, 84 anos)

Outro senhor explica a que ponto teme essa condição:

Eu não tenho medo da morte não, se falar assim: vai morrer amanhã, não tem problema. Eu tenho medo é de, por exemplo, eu sou assim, um pouco agitado, se eu cair numa cama e não puder andar... taí eu tenho medo, de ficar dando trabalho pros outros, ficar pela mão dos outros. Aí é preferível que a gente morresse. [risos] (H18, 65 anos, casado).

Esse medo de dar trabalho é maior até do que o de morrer e revela que ser dependente de outros representa para os idosos: não ter autonomia; não ser capaz de exercer os papéis sociais; de participar da vida social; o que, de certo modo, significa estar morto para o mundo. Além disso, as restrições na participação social repercutem na percepção da saúde: os idosos compreendem a saúde como boa ou razoável, não pela ausência de doenças, mas pela capacidade de interferir no próprio ambiente. Em um trabalho antropológico sobre o construto da percepção da saúde entre idosos de Bambuí, Fonseca et al. ${ }^{19}$ discutiram os significados de saúde nos termos de "participar da vida" e da "ancoragem à vida". O primeiro traz aos idosos sentimentos de serem necessários e de estarem em compasso com o seu tempo; enquanto o segundo compreende a elaboração de estratégias pelo idoso que lhes permita conviver com as mudanças trazidas pelo envelhecimento.

No presente trabalho, quando questionados sobre a razão de algumas pessoas darem trabalho e outras não, os entrevistados relacionaram isso ao destino individual guiado pela vontade de Deus. A fala a seguir demonstra a relevância de Deus para os entrevistados:

Eu penso assim: o que for para mim, Deus me dá, porque não adianta eu falar que eu não vou querer. Ele pode me dar um câncer, ele pode me dar uma doença que eu nem estou pensando. Mas está na mão de Deus (M 5, 77 anos).

Diante disso, a principal ação relatada pelos idosos para evitar dar trabalho era orar e pedir a Deus para morrer antes de ter de passar por essa condição, demonstrando novamente o quão ruim e difícil pode ser dar trabalho, conforme demonstra o relato abaixo:

... medo de dar trabalho os outros eu tenho... É onde eu peço a Deus que Deus me tirar de uma hora para outra sem ser preciso ir para a cama, dar trabalho os outros. Agradeço demais (H 7, 84 anos).

Em Bambuí, a religiosidade - nesse caso, as orações e a busca pelo divino e sagrado - representa uma importante forma de enfrentamento de crise para os idosos, principalmente diante da possibilidade da dependência completa de outros $^{25,26}$. A influência da religião tem sido alvo de pesquisas em vários campos na área da saúde. Sabe-se que a religiosidade é uma estratégia de enfrentamento de crises causadas por problemas de saúde e que possui efeitos benéficos na cura e controle de doenças ${ }^{26}$. Tais estratégias podem ser classificadas como positivas ou negativas, de acordo com a associação a melhores ou piores resultados de saúde física ou mental, e conforme, respectivamente, favoreçam a adesão ao tratamento ou tragam malefícios à saúde, caso levem a abandono ou recusa do tratamento médico ${ }^{27}$.

No grupo estudado, o enfrentamento religioso assumiu papel muito relevante entre as maneiras de lidar com as limitações funcionais. Porém, ele também mostra duas faces: por um lado, ajuda a oferecer conforto nos momentos de crise; por outro, revela a carência de recursos e de alternativas concretas de apoio e de intervenção nos casos mais graves ${ }^{26}$.

A funcionalidade/incapacidade é uma dimensão fundamental na saúde da pessoa idosa que precisa ser mais bem compreendida pelos profissionais de saúde. Dessa forma, em 2001, a Assembleia Mundial da Saúde aprovou a Classificação Internacional de Funcionalidade, Incapacidade e 
Saúde (CIF) que foi traduzida para o português e publicada no Brasil em $2003^{28}$. O conceito chave da CIF é a funcionalidade, que se relaciona com os componentes de funções e estruturas do corpo, atividade e participação social. A funcionalidade é entendida como o aspecto positivo e o aspecto negativo corresponde à incapacidade. Assim, de acordo com esse modelo, a incapacidade é resultante da interação dinâmica entre a disfunção apresentada pelo indivíduo (seja orgânica e/ou da estrutura do corpo), a limitação de suas atividades e a restrição na participação social, e dos fatores ambientais que podem facilitar ou dificultar o desempenho dessas atividades e da participação ${ }^{29}$. Entre os fatores ambientais estão os fatores culturais locais que não estão incluídos nos critérios de classificação, pois precisam ser pesquisados e analisados caso a caso.

Este modelo conceitual, de certo modo, é corroborado pelos dados do presente trabalho, embora nenhum dos entrevistados tenha utilizado os termos e conceitos médicos citados, eles costumam ser reapropriados e reinterpretados pelos entrevistados, uma vez que a experiência da condição de saúde influencia na atribuição do seu significado. A análise aprofundada das narrativas permite afirmar que os idosos compreendem a funcionalidade/incapacidade (disease), como o "dar conta/não dar conta" (illness) e como o "dar trabalho" (illness). Porém, na visão deles, trata-se de condições distintas.

A funcionalidade representa para os idosos dar conta de fazer sozinhos as atividades cotidianas. $\mathrm{O}$ não dar conta se refere às perdas funcionais progressivas atribuídas à velhice, que se iniciam com o parar de trabalhar. À medida que passam a "não dar conta", os idosos lidam com as dificuldades diárias com ações do tipo adaptação, abandono de atividades e ou busca de apoio na família e amigos e se tornam mais quietos, atribuindo essa condição à idade. Ademais, nos registros dos idosos, os profissionais que os atendem nos serviços afirmam que, na velhice, as perdas funcionais são coisas da idade, portanto, nada há a fazer, apenas se conformar. Essa compreensão os priva da promoção da dimensão funcional da saúde, crucial para o próprio construto de saúde neste momento de vida ${ }^{19}$.

No campo de fala dos idosos, dar trabalho é uma condição definitiva, que gera dor e sofrimento à pessoa doente e a quem cuida dela; assim, $\mathrm{o}$ apoio social dos familiares e vizinhos mostra-se fundamental para a sobrevivência e o cuidado dos idosos. Além disso, dar trabalho gera um medo que chega a ser maior do que o da própria morte física e a religiosidade aparece como principal forma de enfrentamento dessa circunstância, enquanto as orações representam a única ação possível, pois somente Deus pode livrá-los desse momento de vida $^{25,26}$.

Portanto, estudar a incapacidade e a funcionalidade, valendo-se da metodologia de Corin et al. ${ }^{18} \mathrm{e}$ das diferenças entre disease e illness estabelecidas por Eisenberg ${ }^{11}$, facilita a compreensão das "maneiras de pensar e agir" dos idosos de Bambuí, quanto às dificuldades diárias e fomenta a compreensão para os serviços de saúde de que a incapacidade não seja uma mera questão física, mas também social e cultural ${ }^{30}$.

\section{Considerações finais}

A visão fatalista da incapacidade como "parte da velhice" está presente na fala dos velhos e no registro das orientações que recebem dos profissionais de saúde, revelando o conformismo com a situação presente na cultura local e nos serviços de saúde. Porém, essa compreensão também demonstra que o desconhecimento da dimensão funcional da saúde pelos profissionais, paradoxalmente, introduz e reforça maiores dificuldades na velhice, comprometendo a qualidade de vida e a saúde dos indivíduos e de suas famílias, além de aumentar a necessidade de cuidados e onerar os serviços de saúde.

Por sua vez, as maneiras de lidar dos idosos nas duas condições - orar, abandonar as atividades, adaptar-se e buscar apoio na família e vizinhos/ amigos - podem revelar a ausência de políticas públicas específicas para aqueles que enfrentam a velhice com dificuldades funcionais. Ressalte-se que, na experiência relatada pelos entrevistados, os serviços de saúde, público e privado, não foram reconhecidos como estratégias para a prevenção e ou o tratamento de condições incapacitantes.

Para quebrar esse ciclo vicioso é necessário reconhecer a relevância da dimensão funcional na atenção e na percepção da saúde da pessoa idosa, investigar os fatores determinantes e agravantes da incapacidade, reduzir o estigma, combater práticas discriminatórias que excluem a pessoa idosa das ações em saúde e fortalecer o empowerment dos indivíduos que vivenciam tais dificuldades. Dessa forma, as intervenções deverão operar na capacitação dos profissionais, na direção dos direitos humanos, da inclusão social, da humanização dos cuidados e de uma visão mais abrangente da funcionalidade, além de promover o efetivo acesso à reabilitação no sistema de saúde e de desfazer o 
mito que associa inexoravelmente a incapacidade e a dependência à velhice.

\section{Colaboradores}

JK Pereira, JOA Firmo e KC Giacomin participaram igualmente de todas as etapas de elaboração do artigo.

\section{Agradecimentos}

À FAPEMIG e à CNPq pelo financiamento.

\section{Referências}

1. Camarano AA. Envelhecimento da população brasileira: uma contribuição demográfica. In: Freitas EV, Py L, Neri AL, Cançado FAX, Gorzoni ML, Rocha SM, organizadores. Tratado de Geriatria e Gerontologia. 3a ed. Rio de Janeiro: Guanabara Koogan; 2006. p. 58-71.

2. Organização das Nações Unidas (ONU). Plano de Ação Internacional para o envelhecimento. Madrid: ONU; 2002. (Série Institucional em Direitos Humanos).

3. Debert GG. A dissolução da vida adulta e a juventude como valor. Horizontes Antropológicos 2010; 34:49-70.

4. Veras R. Envelhecimento populacional contemporâneo: demandas, desafios e inovações. Rev. Saude Publica 2009; 43(3):548-554.

5. House JS. Understanding social factors and inequalities in health: 20th century progress and 21 st century prospects. J Health Soc Behav 2002; 43(2):125-142.

6. Vincent C, Deaudelin I, Robichaud L, Rousseau J, Viscogliosi C, Talbot LR, Desrosiers J, Brad group. Rehabilitation needs for older adults with stroke living at home: perceptions of four populations. BMC Geriatrics 2007; 7:20.

7. Andrade JT, Costa LFA. Medicina complementar no SUS: práticas integrativas sob a luz da Antropologia médica. Saude soc 2010; 19(3):497-508.

8. Sarti CA. Corpo e doença no trânsito de saberes. Rev Bras de Ciências Sociais. 2010 [acessado 2012 nov 18]; 25(74). Disponível em: http://www.scielo.br/pdf/rbcsoc/ v25n74/a05v2574.pdf.

9. Bandura A. Health promotion by social cognitive means. Health Educ Behav 2004; 31(2):143-164.

10. Uchôa E, Vidal JM. Antropologia Médica: Elementos Conceituais e Metodológicos para uma Abordagem da Saúde e da Doença. Cad Saude Publica 1994; 10(4):497504.

11. Eisenberg L. Disease and illness: distinctions between professional and popular ideas of sickness. Cult Med Psychiatry 1977; 1:9-23.

12. Kleiman A. Patients and healers in the context of culture. An exploration of borderland between anthropology and psychiatry. Berkeley: University of Califórnia Press; 1980.

13. Clemente AS, Loyola Filho AI, Firmo JOA. Concepções sobre transtornos mentais e seu tratamento entre idosos atendidos em um serviço público de saúde mental. Cad Saude Publica 2011; 27(3):555-564.

14. Kleinman A, Eisenberg L, Good B. Culture, Illness, and Care: Clinical Lessons From Anthropologic and CrossCultural Research. Focus 2006; IV(1).

15. Instituto Brasileiro de Geografia e Estatística (IBGE). Dados gerais e informações estatísticas da cidade de Bambuí. [Homepage na Internet]. 2009 [acessado 2011 out 18]. Disponível em: http://www.ibge.gov.br/home/estatistica/ populacao/tabuadevida/ 2009/notastecnicas.pdf. 
16. Prefeitura Municipal de Bambuí [Homepage Internet]. [acessado 2012 nov 18]. Disponível em: http://www. bambui.mg.gov.br/portal/htdocs/modules/mastop_publish $/$ tac $=$ Dados_gerais

17. Fontanella BJB, Luchesi BM, Saidel MGB, Ricas J, Turato ER, Melo DG. Amostragem em pesquisas qualitativas: proposta de procedimentos para constatar saturação teórica. Cad Saude Publica 2011; 27(2):388-394.

18. Corin E, Uchoa E, Bibeau G, Kouma-Re B. Articulation et variations des systèmes de signes, de sens et d'actions. Psychopathologie Africaine 1992; 24:183-204.

19. Fonseca MGUP, Firmo JOA, Loyola Filho AI, Uchôa E. Papel da autonomia na autoavaliação da saúde do idoso. Rev Saude Publica 2010; 44(1):159-165.

20. Backes MTS, Rosa LM, Fernances GCM, Becker SG, Meirelles BHS, Santos SMA. Conceitos de saúde e doença ao longo da história sob o olhar epidemiológico e antropológico. Rev.enferm UERJ 2009; 17(1):111-117.

21. Ximenes MA, Concone MHVB. Velhice e trabalho, uma relação possível? Revista Kairós 2009; 6:77-87.

22. Caradec V. Sexagenários e octogenários diante do envelhecimento do corpo. In: Goldenberg M, organizadores. Corpo, envelhecimento e felicidade. Rio de Janeiro: Civilização Brasileira; 2011. p. 21-44.

23. Debert GG. A reinvenção da velhice: socialização e processos de reprivatização do envelhecimento. São Paulo: Edmusp; 1999.

24. Rosa TEC, Benício MHA. As redes sociais e de apoio: o conviver e a sua influência sobre a saúde. BIS, Bol. Inst. Saúde 2009; (47):80-83.

25. Giacomin KC, Santos WJ, Firmo JOA. O luto antecipado diante da consciência da finitude: a vida entre os medos de não dar conta, de dar trabalho e de morrer. Cienc Saude Colet 2013; 18(9):2487-2496.

26. Santos WJ, Giacomin KC, Pereira JK, Firmo JOA. O enfrentamento da incapacidade funcional em idosos por meio das crenças religiosas. Cien Saude Colet 2013; 18(8):2319-2328.

27. Koenig HG, King D, Carson VB. Religion: Good or Bad? In: Koenig HG, King DE, Carson VB. Handbook of Religion and Health. 2a ed. Oxford: Oxford University Press; 2012.

28. Classificação Internacional de Funcionalidade, Incapacidade e Saúde (CIF). Centro Colaborador da Organização Mundial da Saúde para a família de Classificações Internacionais. São Paulo: Edusp; 2003

29. Farias N, Buchalla CM. A Classificação Internacional de Funcionalidade, Incapacidade e Saúde da Organização Mundial da Saúde: Conceitos, Usos e Perspectivas. Rev Bras Epidemiol 2005; 8(2):187-193.

30. Diniz D, Barbosa L, Santos WR. Deficiência, direitos humanos, justiça. SUR - Revista Internacional de Direitos Humanos 2009; 6(11):65-77.

Artigo apresentado em 16/07/2013

Aprovado em 22/02/2014

Versão final apresentada em 28/02/2014 